\title{
Descritores de dor presentes nas narrativas de crianças em tratamento oncológico
}

Luciana Moraes Studart-Pereira. Universidade Federal de Pernambuco.

Ana Augusta de Andrade Cordeiro. Universidade Federal de Pernambuco.

Bianca Arruda de Manchester Queiroga. Universidade Federal de Pernambuco.

\section{Resumo}

A avaliação da dor em crianças necessita de um olhar específico voltado para sua descrição. Considerar aspectos do desenvolvimento cognitivo e linguístico é fundamental na interpretação da experiência dolorosa na população infantil. Trata-se de um estudo de qualitativo que teve como objetivo identificar os descritores de dor presentes nas narrativas de crianças em tratamento oncológico e compará-los aos presentes em um instrumento para adultos. Desenvolvido em um Centro de Oncohepatologia Pediátrico, no período de março a outubro de 2013. A população foi composta por 26 escolares, de ambos os sexos, com idade média de 8 anos e 7 meses. Os resultados apontam que, independentemente da idade, a utilização de reforços figurativos na comunicação oral é bastante presente como apoio na descrição da dor e revelam a necessidade da criação de instrumentos de avaliação de dor adequados às faixas etárias, de forma a facilitar as representações simbólicas em crianças.

Palavras-chave: avaliação da dor, criança, questionário da dor de McGill, narrativa.

\begin{abstract}
Pain descriptors in narratives of children in oncological treatment. The difficulty in assessing pain in children indicates the need for a specific look at the description of the pain. Considering aspects of cognitive and linguistic development is crucial for the interpretation of pain experience in children. The main point of this study was to identify pain descriptors present in the children's narratives which are undergoing cancer treatment and compare them with those present in an instrument for adults. This was a qualitative study conducted in an Oncohepatology Pediatric Center, from March to October of 2013. The sample consisted on 26 students, of both sexes, with an average age of 8 years and 7 months. The results indicate that regardless of age, the use of figurative reinforcements in oral communication is founded as a support in the description of the pain and shows the needing of the creation of assessment pain tools appropriated to each age, in order to facilitate the symbolic representations in children.
\end{abstract}

Keywords: assessment of pain, child, McGill pain questionnaire, narrative.

\section{Resumen}

Descriptores del dolor en las narraciones de los niños en tratamiento oncológico. La dificultad en la evaluación del dolor en los niños indica la necesidad de una mirada específica en la descripción del dolor. Considerar los aspectos del desarrollo cognitivo y lingüístico es fundamental para la interpretación de la experiencia del dolor en los niños. El objetivo del estudio fue identificar los descriptores del dolor presentes en las narrativas de los niños sometidos a tratamiento contra el cáncer y compararlos con los presentes en un instrumento para los adultos. Este fue un estudio cualitativo realizado en un Centro Pediátrico de Oncohepatologia, de marzo a octubre de 2013. La muestra estuvo conformada por 26 estudiantes, de ambos sexos, con una edad promedio de 8 años y 7 meses. Los resultados indican que, independientemente de la edad, el uso de refuerzos figurativos en la comunicación oral es suficiente para mantener a esta en la descripción del dolor y revelar la necesidad de la creación de herramientas de evaluación del dolor apropiadas para cada edad, con el fin de facilitar las representaciones simbólicas en los niños.

Palabras clave: evaluación del dolor, niño, McGill cuestionario del dolor, narrativa. 
Segundo a International Association for The Study of Pain - IASP (1994), a dor é uma experiência sensitiva e emocional, associada à lesão real ou potencial dos tecidos. Trata-se de um fenômeno complexo e de difícil mensuração, principalmente na população infantil. Muitas vezes, na ausência de uma comunicação oral ideal, a avaliação da dor na criança é realizada por meio da observação de sinais tais como alterações posturais e/ ou faciais, atividades autonômicas como a palidez, rubor, sudorese, assim como através de choro, gemido, grito e suspiro. Contudo, tais observações não têm a mesma objetividade que a que é observada no relato (Teixeira, Amaral, Almeida, Protásio, \& Oliveira Filho, 2014).

A ausência de instrumentos para aferir a dor, e que auxiliem na interpretação do processo doloroso na prática clínica, pode comprometer a qualidade da assistência, o correto diagnóstico e direcionamento da terapêutica, assim como os erros que podem advir de uma subavaliação (Sallum, Garcia, \& Sanches, 2012).

Souza, Pereira, Cardoso e Hortense (2010) destacam que para compreender o fenômeno doloroso e avaliar a eficácia das intervenções é necessário conhecer não apenas a intensidade, mas também as respostas motivacionais, cognitivas e afetivas à dor. Portanto, deve ser permitida ao próprio cliente a opção de relatar, descrever e avaliar a sua percepção de dor.

$\mathrm{Na}$ mesma linha, Mathew e Mathew (2003) ressaltam que o autorrelato da dor é considerado na criança, assim como no adulto, o padrão ouro ao acesso à experiência dolorosa, entretanto, o acesso nem sempre é possível. No caso da criança, a narrativa varia com o desenvolvimento dos conceitos que, por sua vez, ocorre em etapas ou estágios sucessivos de maior complexidade, à medida que o desenvolvimento cognitivo avança. Estruturas cognitivas mais desenvolvidas possibilitam a formação de conceitos cada vez mais abstratos e elaborados, evidenciados na capacidade linguística da criança (Tonietto, Pimenta, Duvignau, Gaume, \& Bosa, 2007).

Nesse sentido, é possível afirmar que a percepção do processo doloroso se relaciona ao grau de desenvolvimento cognitivo da criança, que poderá modificar significativamente ao seu relato da dor.

É possível observar modificações significativas no processo de percepção e descrição da dor, ou seja, a capacidade em descrever a dor se torna mais complexa na medida em que a criança avança nos estágios do desenvolvimento. Okada (2001) relaciona esses aspectos aos estágios do desenvolvimento cognitivo propostos por
Jean Piaget e descreve que entre zero e 2 anos de idade, período correspondente ao estágio sensório-motor, haveria ausência de conceitos sobre dor. Já no período entre 2 e 7 anos, período pré-operacional, a criança faz uso de gestos para localizar a dor, sendo essa limitada aos aspectos sensitivos simples, atribuindo características físicas às entidades intangíveis (desenha a dor). A criança entre 7 e 11 anos, no período das operações concretas, ainda segundo o referido autor, percebe a variabilidade da dor, imprevisibilidade e incerteza quanto à duração da dor, atitudes mais ativas, descrevem a dor com termos, qualificativos e afetivos. Finalmente, crianças entre 11 e 14 anos de idade, incluídas no estágio das operações formais, descrevem a dor com termos qualitativos complexos.

Crianças jovens podem fazer referência à intensidade da dor. Existem instrumentos designados para quantificar a severidade da dor, como escalas de categoria numérica/verbal e a escala analógica-visual, que têm sido usadas frequentemente em hospitais e/ou clínicas para se obter informações rápidas, não invasivas e válidas sobre a dor e a analgesia (Sousa, 2002). Contudo, como mencionado, graduam apenas a magnitude da dor.

Com base nas dificuldades em se avaliar a dor em crianças muito pequenas, observadas na prática clínica de profissionais de saúde das mais diversas especialidades e, na ausência de instrumentos adequados que possibilitem não apenas avaliar quantitativamente sua intensidade, mas descrever a experiência dolorosa, considerando o nível do desenvolvimento cognitivo da criança, observa-se lacunas no conhecimento sobre as especificidades da descrição da dor em crianças (Studart, Cordeiro, Lima, \& Queiroga, no prelo).

As modificações dos conceitos de dor, definindo-a como um fenômeno não exclusivamente relacionado à extensão da lesão tecidual, mas também, aos aspectos sensitivo e afetivo da dor, levaram os pesquisadores a buscar formas de avaliação que contemplassem as múltiplas dimensões no processo de avaliação da dor.

Existem instrumentos para adultos, como o Questionário de dor McGill, que, dentre outros aspectos, possibilita a avaliação da experiência dolorosa prevendo um espaço para a queixa espontânea da dor, por meio de um conjunto de palavras que descrevem diversas qualidades das experiências dolorosas em geral e que são escolhidas pelos pacientes para caracterizar as suas dores em particular (Santos, Pereira, Resende, Magno, \& Aguiar, 2006). Tratam-se de descritores de dor caracterizados em subcategorias: "afetivo", "sensitivo" e "avaliativo". 
O Questionário de Dor McGill foi escolhido como parâmetro para o estudo, pois é considerado instrumento universal, capaz de padronizar a linguagem da dor quando se pretende obter informações a partir de descrições verbais (Pimenta \& Teixeira, 1996).

A experiência dolorosa, e, por conseguinte, a sua interpretação, é o resultado da interrelação entre os componentes sensoriais, com os afetivos, cognitivos, neurovegetativos, neuroendócrinos e neuroimunológicos que se expressam frente à estimulação ou disfunção do sistema nociceptivo (Teixeira, Siqueira, \& Alvarez, 2012). Sendo assim, os significados, retratados por meio das dimensões sensorial-discriminativa, motivacional-afetiva e cognitiva-avaliativa, estão sustentados por sistemas fisiologicamente especializados no sistema nervoso central (Pimenta \& Teixeira, 1996). São aspectos da fisiopatologia da dor retratados na descrição da experiência.

O objetivo deste estudo foi identificar os descritores de dor presentes em narrativas de crianças em tratamento oncológico e compará-los aos descritores caracterizados por McGill (1996).

\section{Métodos}

Tratou-se de um estudo de abordagem qualitativa realizado em um Centro de Oncohepatologia Pediátrico no Estado de Pernambuco. O centro é referência no diagnóstico e tratamento de crianças/adolescentes com câncer. Recebe pacientes provenientes da região metropolitana do Recife, do interior do Estado e de estados vizinhos.

A população do estudo foi composta por 26 crianças, com idade média de 8 anos e 7 meses, variando entre 2 anos e 5 meses a 12 anos e 1 mês, de ambos os sexos, que procuraram tratamento de câncer no referido centro, no período de março a outubro de 2013.

Ressalta-se que não foi pretensão desse estudo relacionar a descrição ao problema de saúde da criança. A escolha por essa população foi devida ao fato de que estas crianças já se encontravam vivenciando situações de dor.

O intervalo de idade dos participantes foi determinado considerando os critérios referidos na literatura no que concerne ao período crítico do desenvolvimento da linguagem. Criança com menos de 2 anos de idade ainda não possui habilidade suficiente para narrar histórias, não podendo, dessa forma, transmitir, por meio de enunciados objetivos, a sua experiência de dor. E, por outro lado, crianças maiores que 12 anos, em geral, já atingiram o período de desenvolvimento cognitivo das Operações Formais e não demandam mais elementos concretos para apoiar suas relações simbólicas (Aranda Junior, Silva, \& Fabrin, 2011).

O contato inicial com a criança e seu responsável, bem como o convite para participar da pesquisa, foi realizado na sala de espera, enquanto a criança aguardava atendimento médico. Depois de estabelecido o contato com a criança, sua aceitação em integrar o estudo, e, após autorização de seu responsável, o procedimento aconteceu da seguinte maneira: a criança foi convidada a ir para uma sala reservada e a sentar-se à mesa com a pesquisadora à sua frente. A coleta foi realizada por meio de entrevista semidiretiva. Para favorecer a interação, optou-se por iniciar com questionamentos sobre assuntos gerais, como escolaridade e lazer.

A entrevista seguiu com questionamentos sobre a doença e, mais especificamente, sobre a ocorrência de dor atual e pregressa. Para as 17 crianças que referiram sentir ou já ter sentido dor frequente, foram realizadas as seguintes perguntas-estímulos: Você sentiu ou sente alguma dor? Onde é ou era essa dor? Como é ou era essa sua dor? Com o que ela se parece? Se você pudesse fazer um desenho da sua dor, como ela seria? Sendo as duas últimas, consideradas "perguntas de manga", realizadas apenas nas situações em que as crianças não obtiveram sucesso com os primeiras.

$O$ registro das entrevistas foi realizado por meio de filmagem digital e as mesmas foram transcritas na íntegra. Utilizou-se uma câmera filmadora da marca Sony HDR-CX130 Full HD, fixada em tripé à distância de dois metros da criança.

A pesquisa foi aprovada sob o CAAE $n^{\circ}$ 04860412.3.0000.5208 e seguiu todos os preceitos éticos preconizados na Resolução $n^{\circ}$ 466/2012 do Conselho Nacional de Saúde do Ministério da Saúde. Os responsáveis pelas crianças assinaram o Termo de Consentimento Livre e Esclarecido. Também foi dada a oportunidade de registro de concordância ao menor que desejasse.

\section{Análise dos dados}

Para exploração das falas a partir das entrevistas, foi utilizada a técnica de Análise de Conteúdo Temática de Bardin (2011). De acordo com a autora, esse tipo de análise organiza-se em três etapas: pré-análise; exploração do material e tratamento dos resultados; interferência e interpretação. Na primeira etapa, dá-se a leitura flutuante de todas as falas, para melhor 
operacionalização das ideias. Na segunda, é realizada a leitura exaustiva e profunda, objetivando a codificação dos dados. Na terceira e última etapa, as características pertinentes são sublinhadas em função de suas semelhanças, a partir das quais, são propostas categorias e subcategorias que são confrontadas com achados da literatura.

Nesse sentido, a análise das narrativas das crianças buscou o que estava sendo dito, os sentidos e a lógica do entendimento da dor na perspectiva do paciente, relatada por meio dos enunciados.

Foi feita a opção de selecionar categorias no território lógico-semântico dos pacientes, em que o alcance da Análise de Conteúdo está também vinculado à função de um classificador. Trata-se de uma classificação lógica dos conteúdos manifestos, após a análise e interpretação dos valores semânticos desses mesmos conteúdos.

Os temas emergentes não foram definidos $a$ priori. Os temas e subtemas emergiram do conteúdo da "fala", ou seja, das respostas, e implicaram em uma articulação com as categorias empíricas do senso comum e com as categorias analíticas do referencial teórico. No caso do presente estudo, buscou-se uma categoria que manifestasse uma "qualidade" para a dor.

Na sequência, procedeu-se à análise comparativa entre os descritores de dor categorizados por McGill, validados para o Português por Pimenta e Teixeira (1996).

\section{Resultados e discussão}

Com a finalidade de ilustrar a análise de conteúdo realizada, que culminou com a categoria representativa da "qualidade da dor", será demonstrado, inicialmente, um recorte de fala da criança "05", que desvelou a qualidade da dor como um "choque". Tal análise pode ser observada na Tabela 1.

É importante ressaltar que o mesmo processo foi realizado para se chegar aos demais qualificadores/ descritores presentes no repertório linguístico das crianças do presente estudo, tendo sido observados, além do "choque", já mencionado na Tabela 1, os seguintes descritores: batendo, monte de facas, fina, beliscando, apertada, amassando, fogo, picada, prá lá e pra cá, peso, chata, futicando, grande, horrível, leve, normal, inchada, como uma bola, por dentro, ruim, dodói de sangue e câimbra.

Optou-se pela descrição levando em conta as subdivisões propostas no Questionário de Avaliação de Dor McGill, validado para o Português pelos autores supracitados. O grupo sensorial-discriminativo, na Tabela 2 , refere-se às propriedades mecânicas, térmicas, de vividez e espaciais da dor; o grupo afetivo-motivacional, representados na Tabela 3, descreve a dimensão afetiva nos aspectos de tensão, medo e respostas neurovegetativas; os descritores do componente cognitivo-avaliativo, na Tabela 4, permitem expressar a avaliação global da experiência dolorosa. O grupo Miscelânea (Tabela 5) surgiu da necessidade de inserção de alguns descritores, na oportunidade da elaboração do instrumento, ainda não contemplados nos grupos anteriores.

Como é possível observar, nas narrativas das crianças do estudo, há a ocorrência do uso de palavras concretas e figurativas, refletindo seu estágio de desenvolvimento cognitivo e suas experiências de vida, a exemplo de "picada de maribondo". Embora o questionário McGill tenha dentre suas categorias o descritor "ferroada" e esta expressão tenha o mesmo sentido, o conhecimento desta palavra requer um vocabulário mais elaborado e ampliado, nem sempre disponível no repertório linguístico da criança.

De modo geral, os resultados apontam que as análises das palavras que qualificam a dor que emergiram das narrativas das crianças entrevistadas, demonstraram grande semelhança com os descritores categorizados por McGill (Pimenta \& Teixeira, 1996), como apresentado por Studart, Cordeiro e Queiroga (2014).

Nas divisões "sensitivas" e "avaliativas", foi possível observar maior identificação entre os descritores desse estudo e os propostos pelo instrumento em questão, quando comparados com os integrantes da divisão "afetiva". Isso se deve, provavelmente, à dificuldade com a descrição subjetiva inerente aos descritores relacionados às emoções.

A categoria "afetiva" é composta por palavras relacionadas ao estado emocional do indivíduo, podendo traduzir percepção de cansaço, sentimento de medo e punição e reações autonômicas (Santos et al, 2006). Em contraponto, as "sensoriais" se remetem às percepções e sensações do próprio corpo, adquirindo um caráter mais concreto e mais facilmente descrito pelas crianças.

Observa-se que, de maneira geral, os descritores ressaltados por McGill (Pimenta \& Teixeira, 1996) e presentes nos relatos dos pacientes com dor nada mais são que metáforas da dor, isto é, características conceituais que permitem o compartilhamento da informação, "compreender e experienciar uma coisa em termos de outra" e, dessa maneira, poder "ter 
Tabela 1. Categorização da Qualidade da Dor.

\begin{tabular}{|c|c|c|c|}
\hline Recorte de fala & Núcleo de sentido & $\begin{array}{l}\text { Subtema } \\
\text { Definição da dor }\end{array}$ & $\begin{array}{l}\text { Categoria } \\
\text { Qualidade da dor }\end{array}$ \\
\hline Pesquisadora: Ô C5 você já sentiu alguma dor? & $\begin{array}{l}\text { Pesquisadora: Certo (...), como era essa } \\
\text { dor? }\end{array}$ & $\begin{array}{l}\text { C5: Com (...), é... me esqueci o } \\
\text { nome (...), como câimbra. }\end{array}$ & Choque \\
\hline C5: ((balança a cabeça afirmando)). & C5: Hum? & C5: Não, ele dava choque. & \\
\hline Pesquisadora: Já? & $\begin{array}{l}\text { Pesquisadora: Você falou que parecia } \\
\text { com que? }\end{array}$ & C5: Vive dando choque. & \\
\hline C5: Dor não, choque (( )). & $\begin{array}{l}\text { C5: Com (...), é... me esqueci o nome } \\
\text { (...), com câimbra. }\end{array}$ & & \\
\hline Pesquisadora: Choque é? & Pesquisadora: Parecia com câimbra? & & \\
\hline C5: ((balança a cabeça afirmando)). & C5: (( )), vem de repente. & & \\
\hline Pesquisadora: Como é isso? Onde era na perna? & Pesquisadora: Vem de repente é? & & \\
\hline C5: ((balança a cabeça afirmando)). & C5: ((balança a cabeça afirmando)). & & \\
\hline Pesquisadora: É? Uma só ou nas duas? & $\begin{array}{l}\text { Pesquisadora: Certo, mas você disse } \\
\text { também que parecia com um choque? }\end{array}$ & & \\
\hline C5: ((aponta para a perna)), (( )). & C5: Não, ele dava choque. & & \\
\hline Pesquisadora: É aonde C5? Explica. & Pesquisadora: Dá choque? & & \\
\hline C5: As vezes é nas duas. & C5: Vive dando choque. & & \\
\hline Pesquisadora: É? & Pesquisadora: Há, é? & & \\
\hline C5: Mas já parou um tiquinho. & C5: ((balança a cabeça afirmando)). & & \\
\hline \multicolumn{4}{|l|}{ Pesquisadora: Certo (...), como era essa dor? } \\
\hline \multicolumn{4}{|l|}{ C5: Hum? } \\
\hline \multicolumn{4}{|l|}{ Pesquisadora: Você falou que parecia com que? } \\
\hline \multicolumn{4}{|l|}{ C5: Com (...), é... me esqueci o nome (...), com câimbra. } \\
\hline \multicolumn{4}{|l|}{ Pesquisadora: Parecia com câimbra? } \\
\hline \multicolumn{4}{|l|}{ C5: (( )), vem de repente. } \\
\hline \multicolumn{4}{|l|}{ Pesquisadora: Vem de repente é? } \\
\hline \multicolumn{4}{|l|}{ C5: ((balança a cabeça afirmando)). } \\
\hline \multicolumn{4}{|l|}{$\begin{array}{l}\text { Pesquisadora: Certo, mas você disse também que } \\
\text { parecia com um choque? }\end{array}$} \\
\hline \multicolumn{4}{|l|}{ C5: Não, ele dava choque. } \\
\hline \multicolumn{4}{|l|}{ Pesquisadora: Dá choque? } \\
\hline \multicolumn{4}{|l|}{ C5: Vive dando choque. } \\
\hline \multicolumn{4}{|l|}{ Pesquisadora: Ah, é? } \\
\hline C5: ((balança a cabeça afirmando)). & & & \\
\hline
\end{tabular}

acesso" à experiência do outro (Studart, 2008). No entanto, no exemplo da "ferroada", esses descritores linguísticos nem sempre fazem parte do repertório infantil, não oferecendo o apoio (sentido figurado) para que este (a criança) explicite/descreva a sua dor. Por outro lado, é possível que sendo oferecida a imagem (figura) correspondente ao descritor, tal metáfora seja possível.

Esse compartilhar de metáforas é, sem dúvida, um relevante instrumento na construção do diagnóstico mas, principalmente, para o entendimento da experiência do sujeito que sofre.
Alves e Rabelo (1999), ao falarem das narrativas de aflição que podem ser estendidas a outras narrativas, inclusive as da dor, dizem que: as metáforas desempenham papel central, constituem estratégias de inovação semântica, que estendem sentidos habituais para domínios inesperados, oferecendo assim uma ponte entre a singularidade da experiência e a objetividade da linguagem, das instituições e dos modelos legitimados socialmente. Tecidas em uma narrativa, as metáforas dão forma ao sofrimento individual e apontam o sentido de resolução desse sofrimento: permitem aos indivíduos organizar sua experiência subjetiva, de modo a transmiti-la aos outros - familiares, 
Descritores de dor presentes nas narrativas de crianças em tratamento oncológico

Tabela 2. Comparação entre os Descritores Emergentes nas Narrativas das Crianças e os de McGill da Divisão Sensitiva.

\begin{tabular}{|c|c|}
\hline McGill & Crianças \\
\hline Como batidas & Batendo \\
\hline \multicolumn{2}{|l|}{ Como pancadas } \\
\hline \multicolumn{2}{|l|}{ Pontada } \\
\hline Choque & Choque \\
\hline \multicolumn{2}{|l|}{ Tiro } \\
\hline \multicolumn{2}{|l|}{ Agulhada } \\
\hline \multicolumn{2}{|l|}{ Perfurante } \\
\hline Facada & Monte de facas \\
\hline \multicolumn{2}{|l|}{ Punhalada } \\
\hline \multicolumn{2}{|l|}{ Em lança } \\
\hline Fina & Fina \\
\hline \multicolumn{2}{|l|}{ Cortante } \\
\hline \multicolumn{2}{|l|}{ Estraçalha } \\
\hline Beliscão & Beliscando (formiga) \\
\hline Aperto & Apertada \\
\hline \multicolumn{2}{|l|}{ Mordida } \\
\hline \multicolumn{2}{|l|}{ Cólica } \\
\hline Esmagamento & Amassando (caminhão passando) \\
\hline \multicolumn{2}{|l|}{ Fisgada } \\
\hline \multicolumn{2}{|l|}{ Puxão } \\
\hline \multicolumn{2}{|l|}{ Em torção } \\
\hline \multicolumn{2}{|l|}{ Calor } \\
\hline Queimação & Fogo \\
\hline \multicolumn{2}{|l|}{ Fervente } \\
\hline \multicolumn{2}{|l|}{ Em brasa } \\
\hline \multicolumn{2}{|l|}{ Formigamento } \\
\hline \multicolumn{2}{|l|}{ Coceira } \\
\hline \multicolumn{2}{|l|}{ Ardor } \\
\hline Ferroada & Picada (marimbondo) \\
\hline Mal localizada & Pra lá e pra cá \\
\hline \multicolumn{2}{|l|}{ Dolorida } \\
\hline \multicolumn{2}{|l|}{ Machucada } \\
\hline \multicolumn{2}{|l|}{ Doída } \\
\hline Pesada & Peso \\
\hline \multicolumn{2}{|l|}{ Sensível } \\
\hline \multicolumn{2}{|l|}{ Esticada } \\
\hline \multicolumn{2}{|l|}{ Esfolante } \\
\hline \multicolumn{2}{|l|}{ Rachando } \\
\hline Sensível & \\
\hline
\end{tabular}

amigos, terapeutas - e a desencadear nesses uma série de atitudes condizentes com uma nova situação apresentada.

Estes dados reforçam a necessidade de que, para o processo de avaliação de dor em crianças, a utilização
Tabela 3. Comparação entre os Descritores Emergentes nas Narrativas das Crianças e os de McGill da Divisão Afetivo.

\begin{tabular}{l} 
McGill Crianças \\
\hline Cansativa \\
Exaustiva \\
Enjoada Apertada (enforcando) \\
Sufocante \\
Amedrontadora \\
Apavorante \\
Aterrorizante \\
Castigante \\
Atormentada \\
Cruel \\
Maldita \\
Mortal \\
Miserável \\
Enlouquecedora
\end{tabular}

Tabela 4. Comparação entre os Descritores Emergentes nas Narrativas das Crianças e os de McGill da Divisão Avaliativo.

\begin{tabular}{lc}
\hline McGill & Crianças \\
\hline Chata & Chata \\
Que incomoda & Futicando \\
Desgastante & \\
Forte & Forte (Grande) \\
Insuportável & Horrível \\
\hline
\end{tabular}

Tabela 5. Comparação entre os Descritores Emergentes nas Narrativas das Crianças e os de McGill da Divisão Miscelânea.

\begin{tabular}{ll}
\hline McGill & Crianças \\
\hline Espalha & \\
Irradia & \\
Penetra & \\
Atravessa & Apertada (fechando) \\
Aperta & \\
Adormece & \\
Repuxa & \\
Espreme & \\
Rasga & \\
Fria \\
Gelada \\
Congelante \\
Aborrecida \\
Dá náusea \\
Agonizante \\
Pavorosa \\
Torturante
\end{tabular}


de recursos concretos, facilmente reconhecíveis, que possibilitem a identificação da dor, favorece o uso do repertório linguístico compatível com o desenvolvimento da criança, durante a avaliação da experiência dolorosa, eliminando a barreira lexical e aproveitando ao máximo a experiência de vida da criança.

Durante o processo de validação para língua portuguesa, realizado por Pimenta e Teixeira (1996), constatou-se que algumas das palavras (descritores) do questionário de McGill são sinônimos entre si, outras parecem sinônimos, mas variam em intensidade, e ainda há os que apresentam diferenças mínimas ou nuances que podem ser importantes para as pessoas que estão tentando comunicar sua dor.

Contudo, destacam-se alguns descritores presentes no universo linguístico infantil e em algumas narrativas desse estudo, a exemplo de leve, normal, inchada, como uma bola, por dentro, ruim, dodói de cãibra, os quais não integram o referido instrumento.Com o propósito de demonstrar os descritores observados nas falas das crianças, bem como suas dificuldades em explicitá-los, considerando os estágios do desenvolvimento cognitivo, seguem alguns trechos de narrativas transcritas a partir das perguntas-estímulos.

\section{Criança 03}

Pesquisadora: E como é essa dor?

Criança: Dói que só.

Pesquisadora: Mas como? Se tu pudesse me dizer... como é essa dor que tu sente?

Criança: Pensando que eu... que eu tô fazendo um negócio... que tá batendo neu (em mim).

$\mathrm{Na}$ fala da criança acima, com $10 \mathrm{dez}$ anos de idade, que descreve a dor causada durante a realização de um exame, apesar de ser possível apontar um descritor de dor, nota-se a dificuldade com a exposição. O paciente compara o evento doloroso à sua experiência de vida. Nesse caso, fica a dúvida se a dor se assemelha à sensação batida/pancada na superfície da pele, como punição corporal, ou a eventos anteriormente vivenciados, como outras experiências de dor. Mc Grath, Noel, Chambers, Klain e Stewart (2012) encontraram que há fatores, como ansiedade, que podem se relacionar à memória da dor e também devem ser considerados. São questões a serem destacadas pelos profissionais de saúde no momento da avaliação da dor, pois características da descrição direcionam o diagnóstico e definem a indicação terapêutica.

\section{Criança 12}

Pesquisadora: Você consegue me dizer como era essa dor?

Criança: Era uma dor por dentro, forte, muito forte.

Pesquisadora: Certo, mas você consegue me dizer a sensação da dor?

Criança: Ruim.

Pesquisadora: Ruim né? Era uma sensação ruim?

Criança: ((balança a cabeça afirmando)).

Pesquisadora: Mas se você conseguisse é...você conseguiria me dizer com que ela se parecia?

Criança: Assim, um monte de faca por dentro.

A propriedade com que essa criança, de 12 anos, descreve a dor proveniente de um tumor no braço é um bom exemplo para se refletir que a memória da dor pode ser relativa à qualidade, intensidade e frequência. A narrativa é iniciada com informações sobre localização (por dentro), intensidade (forte), mas, finalmente, consegue associar a "um monte de facas por dentro".

A criança, gradualmente, torna-se capaz de expressar verbalmente fatos ocorridos no passado, da mesma maneira que o faz com episódios recentes, por meio da linguagem. Todavia, percebe-se que a intensidade dos eventos dolorosos pode ser um determinante para a facilitação da descrição.

\section{Criança 17}

Criança: Aí todo dia eu tinha mania de correr lá no campo, atrás de casa. Quando eu parava essa dor batia. Do lado da barriga. Pegava do meio até aqui atrás.

Pesquisadora: Certo. Mas se você pudesse dizer a sensação da dor... como era que tu sentia ela?

Criança: Horrível... horrível!

Pesquisadora: É! E se tu pudesse me dizer, assim, com o que ela se parecia?

Criança: Deixa eu ver... com uma picada de marimbondo... porque eu já levei uma aqui no nariz e meu nariz ficou inchado. Doeu muito.

\section{Criança 15}

Pesquisadora: Mas aí, quando ela vinha... tu sentia como?

Criança: Como uma formiguinha coisando.

Pesquisadora: Ah! Como? Fala de novo!

Criança: Uma formiguinha beliscando.

Pesquisadora: Ah! Como uma formiguinha beliscando, era? E ela beliscava forte ou fraco? 
Criança: Forte.

Os exemplos acima, referentes às crianças de 10 anos e 4 meses e 6 anos e 8 meses respectivamente, apontam para a necessidade de estabelecer analogias entre as sensações e experiências concretas presentes no universo infantil. "Picada/fina" e "beliscão" são descritores da lista de McGill (Pimenta \& Teixeira, 1996), mas aqui aparecem apoiados por elementos (animais) do conhecimento das crianças, representados por metáforas "formiguinha beliscando".

Em se tratando de experiência da dor, como ressaltam Studart e Acioli (2011), essa passa a ser linguisticamente possível de ser formatada por meio de imagens que lembrem experiências físicas como queimar, perfurar, pisar, formigar, entre outras. É a sensação tomando forma, adquirindo significado e possibilitando o entendimento do interlocutor, associada ao compartilhamento dos "conceitos metafóricos".

\section{Criança 02}

Pesquisadora: Onde era essa dor?

Criança: Era aqui (passando a mão na barriga) é... na parte embaixo da barriga.

Pesquisadora: certo, e como era essa dor?

Criança: Muito forte, muito forte mesmo.

Pesquisadora: Certo, mas como era? Será que você poderia me descrever como ela era?

Criança: Assim, quando eu sentia dor era assim... a mesma coisa que um peso dentro da barriga alguma coisa querendo descer, alguma coisa... alguma coisa dentro hum... muito apertado (passa a mão na barriga) não sei... muito grande, muito ruim.

A criança acima, de 11 anos e 7 meses de idade, utiliza de orientação relacionada às questões espaciais do tipo: para cima - para baixo, dentro - fora, frente - trás, em cima de - fora de, fundo - raso, central - periférico, para descrever o fenômeno doloroso. Quando ela diz: alguma coisa querendo descer, trata-se de uma metáfora Orientacional, segundo Lakoff e Johnson (2002).

Essas orientações espaciais surgem do fato de termos os corpos que temos e do fato de eles funcionarem da maneira como funcionam no nosso ambiente físico. As metáforas não são arbitrárias, e aqui podemos destacar os demais descritores "forte, apertado, peso, grande, ruim", mas baseadas na experiência física e cultural que temos. Elas têm a ver com noções espaciais, a vivência, a experiência estética, a comunicação, a autocompreensão, enfim, com a forma do sujeito ser e se relacionar com o mundo. Nesse aspecto, o corpo é uma referência a partir da qual entra-se em relação com o mundo exterior e, com base nessa relação, são organizados conceitos coerentes com a cultura na se está inserida (Lakoff \& Johnson, 2002).

\section{Criança 16}

Pesquisadora: Entendi! E essa dor que você sentia nas pernas? Você consegue me descrever como era?

Criança: Sim... era muito forte. Era tipo que tava amassando assim... amassando tipo a perna.

Pesquisadora: Se você pudesse pensar numa coisa, num desenho... como é que seria?

Criança: Um caminhão passando na minha perna.

Novamente são feitas alusões ao concreto. A imagem do caminhão, um veículo de grande porte, referida pela criança de 12 anos, esclarece a "imagem" do amassamento além de transmitir a conceito de intensidade.

Sobre os descritores de intensidade, Camargo (2001) em abordagem clínica, afirma que a dor é descrita de modo diferente, conforme a linguagem habitual do doente, mas sempre salientando a intensidade e o sofrimento que provoca.

\section{Criança 17}

Pesquisadora: E você lembra como era essa dor?

Criança: Lembro! É porque eu sempre corria muito... aí toda vez que eu corria a dor não batia não. Aí quando eu parava e sentava, começava aquela dor chata. Aí, a partir desse dia, minha vó foi dar banho em mim e viu o caroço do lado da minha barriga. Aí me levou para Buenos Aires, fez uma ultrasson e suspeitou de baço, mas não era baço. Encaminhou aqui pro Recife. Fui no IMIP, mas não tinha vaga. Vim pra aqui tinha vaga, se internei e hoje eu tô aqui.

Pesquisadora: E me diga uma coisa, como era essa dor? Se tu pudesse me dizer, assim, exatamente como ela era... como é que tu me diria?

Criança: Essa dor era meia chata. Ela pegava mais ou menos daqui (apontando), do meio da barriga prá cá... do lado do rim.

McGill incluiu "chata" na divisão Avaliativo (avaliação da experiência global), juntamente com "que incomoda", "desgastante", "forte" e "insuportável" (Pimenta \& Teixeira, 1996). Paralelamente, em uma perspectiva de metáforas pode ser caracterizada como Personificadas, ou seja, objetos físicos e experiências são concebidos como pessoas (uma pessoa chata) (Lakoff \& Johnson, 2002). Isso nos permite compreender 
uma grande variedade de experiências concernentes a entidades não-humanas em termos de motivações, características e atividades humanas.

\section{Criança 09}

Pesquisadora: Como é que ela? Ela parecia com o que? Se você pudesse fazer um desenho dessa dor que desenho você faria dela?

Criança: Assim eu sentia dor só quando eu ficava em pé né? Só que as vezes quando eu ia sentar eu não aguentava sentar por causa da dor, e a dor também ela... não tem quando a gente é... a perna fica inchada?

Pesquisadora: Ah! Sim.

Criança: Aí é assim.

Pesquisadora: Parecendo quando a perna fica inchada?

Criança: É.

Pesquisadora: A sensação?

Criança: (balança a cabeça afirmando).

\section{Criança 14}

Pesquisadora: Se tu pudesse me explicar qual é a sensação, o que é que você sente? Tu conseguiria me explicar?

Criança: Eu sinto... uma dor.

Pesquisadora: Certo, ela se parece com o que, essa dor?

Criança: Com uma bola.

Pesquisadora: Com uma bola?

Criança: (balança a cabeça afirmando).

Pesquisadora: É? Certo, mas se você pudesse fazer um desenho, tá certo... dessa dor? Que desenho você faria dela?

Criança: A minha perna, e isso aqui inchado (colocando a mão sobre o joelho).

As crianças acima, com 7 anos e 5 meses e 8 anos respectivamente, descrevem a dor como sensação de volume. Chegam a ressaltar o termo inchado, que não é lembrado por McGill (Pimenta \& Teixeira, 1996). Contudo, por outro lado, mais uma vez, são utilizadas analogias e sentidos figurados - como uma bola.

\section{Considerações finais}

As palavras que qualificam a dor, emergentes das narrativas das crianças entrevistadas nesse estudo demonstraram grande semelhança com os descritores categorizados por Mcgill (Pimenta \& Teixeira, 1996). Dos 24 selecionados, 17 são coincidentes ou semelhantes.
Percebeu-se ainda, que independente da idade, a utilização de reforços figurativos na comunicação oral, conhecida no campo dos estudos da linguagem como metáforas, é bastante presente como apoio na descrição da dor.

O apelo ao concreto, significativamente presente no universo linguístico infantil, colaboram para a representação das metáforas, refletem o estágio de desenvolvimento cognitivo das crianças e apontam para a necessidade da criação de instrumentos multidimensionais de avaliação de dor adequados às faixas etárias e que utilizem o concreto.

Acredita-se que a categorização dos descritores presentes no auto-relato infantil, assim como no auto-relato adulto, facilita o estabelecimento do diagnóstico, pois a definição das sensações podem contribuir de maneira significativa para a restrição das hipóteses diagnósticas e auxiliar o entendimento do profissional de saúde, bem como melhor condução da conduta terapêutica a ser adotada.

Os resultados desse estudo apontam para a importância de se considerar o estágio do desenvolvimento cognitivo em que a criança se encontra e a possibilidade de expressão do evento doloroso. Dessa forma, revela a necessidade de instrumentos de avaliação de dor, usarem imagens/figuras/terminologias que façam alusão ao concreto, independente de o objetivo ser a mensuração da intensidade ou identificação dos aspectos qualitativos da experiência dolorosa.

A multidimensionalidade da dor exige um cuidado especial no seu manejo. Todos os componentes devem ser investigados. Além da intensidade e qualidade da dor, mencionados ao longo desse estudo, aspectos como localização e frequência integram a complexidade desse fenômeno. Dessa maneira, é preciso estar alerta para que a abordagem e os instrumentos utilizados para avaliação da experiência dolorosa sejam condizentes com o desenvolvimento da criança e valorizem as experiências de cada uma.

\section{Referências}

Alves, P.C.B., \& Rabelo, M.C.M. (1999). Significação e metáfora na experiência da enfermidade. In M. C. M. Rabelo, P.C. B. Alves \& I. M. A. Souza (Orgs.), Experiência da doença e narrativa (pp. 171-186). Rio de Janeiro: Fiocruz.

Bardin, L. (2011). Análise de conteúdo. Lisboa: Edições 70.

Camargo, A. C. (2001). Dor: diagnóstico e tratamento. São Paulo: Roca. Aranda Junior, W., Silva, F. A., \& Fabrin, A. P. D. P. (2011). Desenvolvimento de uma ferramenta para educação no trânsito, baseado em teorias do desenvolvimento cognitivo de piaget. Colloquium Exactarum, 3(2), 124-132. Recuperado de http://revistas.unoeste. br/revistas/ojs/index.php/ce/article/viewArticle/717 
Descritores de dor presentes nas narrativas de crianças em tratamento oncológico

Lakoff, G., \& Johnson, M. (2002). Metáforas da vida cotidiana. São Paulo: PUC.

Mathew, P. J., \& Mathew, J. L. (2003). Assessment and management of pain in infants. Postgraduate Medical Journal, 79(934), 438-443. doi: 10.1136\%2Fpmj.79.934.438

Mc Grath, P., Noel, M., Chambers, C. T., Klain, R. M., \& Stewart, S. H. (2012). The role of state anxiety in children's memories for pain. Journal of Pediatric Psychology, 37(5), 567-579. doi: 10.1093/ jpepsy/jss006

Okada, M., Teixeira, M. J., Tengan, S. K., Bezerra, S. L., \& Ramos, C. A. (2001). Dor em pediatria. Revista de Medicina, 80, 135-156. doi: 10.11606/issn.1679-9836.v80i0

Pimenta, C. A. M., \& Teixeira, M. J. (1996). Proposta de adaptação do questionário de dor McGill para a Língua Portuguesa. Revista da Escola de Enfermagem da USP, 30(3), 473-483. doi: 10.1590/ S0080-62341996000300009

Resolução no 466, de 12 de outubro de 2012 (2012, 12 de outubro). Diretrizes e normas regulamentadoras de pesquisas envolvendo seres humanos. Brasília, DF: Ministério da Sáude, Conselho Nacional de Saúde.

Sallum, A. M. C., Garcia, D. M., \& Sanches, M. (2012). Dor aguda e crônica: Revisão narrativa da literatura. Acta Paulista de Enfermagem, 25(1), 150-154. doi: 10.1590/S0103-21002012000800023

Santos, C. C., Pereira, L. S. M., Resende, M. A. Magno, F., \& Aguiar, V. (2006). Aplicação da versão brasileira do questionário de dor Mcgill em idosos com dor crônica. Acta Fisiátrica, 13(2), 75-82. doi: 10.5935/0104-7795.20060002

Sousa, F. A. E. F. (2002). Dor: O quinto sinal vital. Revista Latino-americana de Enfermagem, 10(3), 446-447.
Souza, F. F., Pereira, L. V., Cardoso, R., \& Hortense, P. (2010). Escala multidimensional de avaliação de dor (EMADOR). Revista Latino-Ameriacana de Enfermagem, 18(1), 3-10. doi: 10.1590/S0104-11692010000100002

Studart, L., \& Acioli, M.D. (2011). Pain communication: a study of narratives about the impacts of the temporomandibular disorder. Interface - Comunicação, Saúde, Educação, 15(37), 487-503. doi: 10.1590/ S1414-32832011005000011

Studart, L. M. (2008). A linguagem da dor: um estudo dos enunciados de sujeitos portadores de disfunção temporomandibular (Dissertação de Mestrado). Universidade Católica de Pernambuco. Recuperado de: http://www.unicap.br/tede/tde_arquivos/2/TDE-2010-0507T195232Z-264/Publico/dissertacao_luciana_studart.pdf

Studart, L., Cordeiro, A. A. C., \& Queiroga, B. A. M. (2014). Descritores de dor presentes nas narrativas de crianças com câncer. In Resumos do $11^{\circ}$ Congresso Brasileiro de dor da Sociedade Brasileira para Estudos da Dor (p. 91). São Paulo, SP.

Studart, L., Cordeiro, A. A. C., Lima, L. S., \& Queiroga, B. A. M. (no prelo). Descrição de dor em crianças: uma revisão integrativa. Journal of Nursing UFPE.

Teixeira, M. J., Siqueira, J.T.T., \& Alvarez, F. K. (2012). Fisiopatologia da dor/Glossário de Termos para Semiologia da Dor. In Siqueira, J. T.T. \& Teixeira, M. J. (Orgs.), Dores orofaciais: diagnóstico e tratamento. (pp.61-81). São Paulo: Artes Médicas.

Teixeira, P. A. P., Amaral, L. T., Almeida, L. R. M., Protásio, J. C. R, \& Oliveira Filho A. M. (2014). Manejo da dor pós-operatória: uma revisão bibliográfica. Revista de Medicina e Saúde de Brasília, 3(1), 85-89. Recuperado de http://portalrevistas.ucb.br/index.php/rmsbr/ article/view/4580

Tonietto, L., Parente, M. A. M. P., Duvignau, K., Gaume, B., \& Bosa, C. A. (2007). Aquisição inicial do léxico verbal e aproximações semânticas em português. Psicologia: Reflexão e Crítica, 20(1), 114-23. doi: $10.1590 /$ S0102-79722007000100015

Luciana Moraes Studart-Pereira, Doutora em Saúde da Criança e do Adolescente pela Universidade Federal de Pernambuco (UFPE), é Professora Adjunta do curso de graduação em Fonoaudiologia da Universidade Federal de Pernambuco (UFPE). Endereço para correspondência: Av. Boa Viagem, 110/1301 - Boa Viagem Recife/ PE - CEP: 51011-000. Telefones para contato: (81) 30343283 e (81) 988048804. E-mail: luciana.studart@uol.com.br

Ana Augusta de Andrade Cordeiro, Doutora em Psicologia Cognitiva pela Universidade Federal de Pernambuco (UFPE), é Professora Associada do curso de graduação em Fonoaudiologia da Universidade Federal de Pernambuco (UFPE). E-mail: anaaugusta_cordeiro@yahoo.com.br

Bianca Arruda de Manchester Queiroga, Doutora em Psicologia Cognitiva pela Universidade Federal de Pernambuco (UFPE), é Professora Associada do curso de graduação em Fonoaudiologia da Universidade Federal de Pernambuco (UFPE) e Docente Colaboradora do Programa de Pós-graduação em Saúde da Criança e do Adolescente. E-mail: queiroga.bianca@gmail.com 